\title{
Intrusive Teaching: The Strain of Care Labor, Identity, and the Emerging Majority in Higher Education
}

\author{
Jayne Goode (1) \\ Katherine J. Denker () \\ Daniel Cortese (1) \\ Lisa Carlson \\ Kerri Morris (1)
}

Keywords: care labor, emerging majority, intrusive teaching, role strain

\begin{abstract}
United States publicly-funded higher education systems are experiencing increasing pressures (Chronicle of Higher Education, 2019). In response, higher education institutions have broadened their appeal to students less likely to attend college as part of their fiscal strategies (Carlson, 2019). This growing student population consists of first-generation students and individuals from marginalized backgrounds who often enter college underprepared (Crissman Ishler, 2005), and higher education must retain these emerging-majority students to ensure fiscal stability (Soria \& Stebleton, 2012). When enrollment and retention are viewed from a business model (Kelderman, 2019), faculty duties expand into triage care and student emotional support. This qualitative investigation of faculty in a publicly-funded state university explores intrusive teaching practices marked by monitoring and intervening in their students' emotional and social issues.
\end{abstract}

United States publicly-funded higher education systems are experiencing increasing pressures to operate under a business model to supplant decreasing legislative funding (Carlson, 2019; Chronicle of Higher Education, 2019; Kelderman, 2019). Mitchell et al. (2018) argue that spending on education in 2018 fell $\$ 7$ billion below 2008 levels after adjusting for inflation. Legislative decisions, most predominantly cuts 
to taxes which make up the majority of institutional support, have left public universities scrambling for additional sources of revenue to supplant the costs. In the current fiscal climate, state universities have sought to broaden their appeal to students less likely to attend college.

A growing number of first-generation students, individuals from marginalized backgrounds, and racial and ethnic minorities are entering college (Anderson, 2003; Crissman Ishler, 2005). These students face daunting challenges that limit their retention because they are less familiar with college culture or with its underlying hidden curriculum (Horn, 2003; Smith, 2013). All students need to find support in the university environment (Tinto, 1987). However, the task is even more critical for emerging majority students who may lack the "capital" (Bourdieu, 1986) that are necessary for academic success.

Faculty are still evaluated on their content knowledge and classroom maintenance. However, out of sheer necessity in implementing higher education directives, they are also now required to operate as a nexus of social and emotional support resources within the institutional contexts of "best-practices in serving students" as part of the effort to increase student retention and persistence of the most vulnerable students. In the contexts of teaching, faculty perform care labor. This caregiving labor requires faculty to engage in intrusive teaching, providing an increasing and intensive social and emotional support for students, which has altered the very fabric of the professoriate and shifted identities (Lawless, 2018).

The purpose of this investigation is to understand the identity negotiations experienced because of the new care labor demands of institutions with emerging majority populations. Specifically, this qualitative investigation will uncover the nature of these new labor demands and how faculty adapt to the shifting responsibilities of the professoriate from traditional academic tasks to care labor. Further, this article will provide justification for a new conceptual framework for this expected labor in intrusive teaching.

\section{Literature Review}

College environments represent opportunities for those underserved in previous academic endeavors. Research has sought to identify factors influencing the success of these "non-traditional" students. Typically, these students have been older than 24 years, lived off-campus, and were part-time (Athens, 2018). Non-traditional students or "returning students" often started at the community college level and then, with success, entered the 4-year institution (NSC Research Center, 2019). Factors decreasing the retention of non-traditional students include psychological issues, social, and environmental factors (Bean \& Metzner, 1985; Lohfink \& Paulsen, 2005; Longwell-Grice, 2003). These issues are not unknown to 4-year institutions. However, once students had successfully navigated through the community college, they had demonstrated the potential to manage external challenges. Further, transfers of the non-traditional student were a significantly smaller portion of the overall student population than traditional students for most institutions.

These trends, however, are quickly changing. Due to increased budgetary pressures and decreased state support (Mitchell et al., 2018), greater tuition revenue is critical for university survival. Thus, universities have sought to expand their target audience to more non-traditional first-year students, termed the "emerging majority" (Anderson, 2003; Betances, 2004; Laden, 2004). They often come from economically challenged backgrounds, have caregiving responsibilities, and are more likely to identify as students of color (Araújo et al., 2014; Athens, 2018; Whitford, 2019). Further complicating the road to success are expectations that students, who have little socialization into higher education or social network support, are unable to navigate. 
Adequate preparation for this student population is critical for their success (Cabrera et al., 1993). Retention of students is related to key factors such as feeling connected to the institution, which is established through interaction with peers, faculty, and staff (Cabrera et al., 1993; Hrabowski, 2005). A sense of belonging within the academic institutions is essential for students' academic success, "particularly for the retention of students who are considered to be at risk of non-completion" (O'Keeffe, 2013, p. 607).

Tinto (2006) argued that for these students to be successful in their first year, faculty must take a personal role in ensuring their retention. This new faculty expectation to maintain tuition revenue streams from non-traditional students, however, has unintended consequences in faculty identity issues and emotional labor. Faculty are tasked with being essential anchors for the emerging-majority students, who upon entering the university often have little understanding of the social norms of higher education and a host of unaddressed personal and social issues which can interfere with classroom performance and, therefore, retention. It is in the context of this system, that the role and identity of faculty must be interrogated.

\section{Identity Theory and Role-Based Identities}

At the intersection of shifting cultural factors and an internal motivation to shape higher education sits identity theory. Instructional communication scholars have noted identity theory's centrality in understanding the impact of communicative constructs and classroom interactions (e.g., Pearson et al., 2011). However, Hosek and Soliz (2016) argued that "instructional researchers have paid little attention to the ways in which personal and social factors influence the classroom context rendering the complexities of identity and multidimensionality relatively invisible" (p. 223). They also suggested that a more comprehensive look at instructional communication should attend to the influence of identities, as "these can enhance or diminish self-efficacy, self-esteem, and job satisfaction for teachers" (Hosek \& Soliz, 2016, p. 223). Though other identity-based theories have emerged, Hogg et al. (1995) noted, "identity theory may be more effective in dealing with chronic identities and with interpersonal social interaction" (p. 255).

Identity theory views the "self as a compressive social construct emerging from one's roles in society," like that of the college professor (Pearson et al., 2011, p. 217). Grounded in the work of Mead (1934) and Stryker (1968), Burke (1980) noted "the idea of role/identities as sub-units of the self is not new" (p. 18), rather in tying them to positions in the social structure it makes "much more tractible the problematics of the link between identity and performance" (p. 18). It is precisely at this intersection where we turn to the struggle of faculty working with the emerging majority. These role identities are important not only in understanding self-conceptions, but also as they distinguish roles from complementary or counter roles (Hogg et al., 1995) as the role of the professor takes on meaning in interaction with that of the student.

Through discourse, our roles and identity come to take on further meaning, as "identity is the pivotal concept linking social structure with individual action" (Hogg et al., 1995, p. 257). Roles and identity are further shaped by identity salience, with those roles higher on the hierarchy of our own identities being more likely to influence behavior (Hogg et al., 1995). Hogg and Terry (2000) argued that "social identity processes are motivated by subjective uncertainty reduction" (p. 122). Moreover, group identities have been shown to shape instructional outcomes like communication satisfaction and affect for instructors (Hosek, 2015). 
As college campuses struggle (Kimbark et al., 2017), the role expectations for faculty are in transformation and research has only begun to examine faculty perceptions of this role conflict/overload (See Anderson et al., 2019). To handle these new experiences, the duties of faculty have expanded to handle completely different role expectations and now more readily resemble care labor.

\section{Care Labor}

In day-to-day discussions, applications of material, and reflective assignments, faculty may now be exposed to students' trauma because of assault, food insecurities, and other similar issues in their classroom (King \& Wheeler, 2019). Further, as faculty are expected by some to be anchors of student integration (Tinto, 2006), the burden of helping students manage emotional, mental, and social marginalization becomes an unwritten ascribed duty. Thus, care labor is not contractually mandated, nor taught in preparatory graduate work, but is nonetheless an essential part of classroom management for institutions that serve the emerging majority student.

Despite their important functions, emotions in organizations historically have been disregarded, privileging the rational and denigrating the emotional (Fineman, 1993). In addition, emotional labor may have acquired gendering, being seen as "women's work" (Erickson \& Ritter, 2001; Hochschild, 1983). In response to this subordination of emotion in organizations, communication scholars see the overwhelming importance of acknowledging emotion's significant role (Dougherty \& Drumheller, 2006; Fineman, 1993). While emotion is still seen as inferior to the rational in organizations, workers display certain emotions and create emotions in others as a part of their job in what Hochschild (1983) defined as emotional labor. Lawless (2018) further argued, "the scholarly conversation about academic labor has largely ignored emotional labor, especially within communication studies literature" (p. 86) with the exception of a few sources (e.g., Anderson et al., 2019; Lawless \& Chen, 2019).

Care work can be defined as positions that require care of others as one's primary responsibility, including childcare, eldercare, nursing, and social work (Erickson \& Stacey, 2013). Erickson and Stacey (2013) noted, "The term caring labor also signifies the complexity, ambiguity, and embedded contradictions that characterize the emotion management performed in human service jobs-jobs, that exemplify the tension between 'relationships versus rules"' (p. 178). Sass (2000) constructively detailed the differences between emotional labor in retail positions and human services positions. Often, human services emotional labor involves longer relationships with clients/patients, and power structures may vary. For example, nurses may feel more powerful than patients, whereas cashiers rarely feel more powerful than customers. However, nurses must still ensure patients' comfort and satisfaction, making these relationships between caring laborers and clients/patients even more complex.

However, public service jobs (which are also caring labor jobs) typically work with vulnerable populations (Mastracci et al., 2012). Putnam and Mumby (1993) viewed social workers' emotional labor uniquely as occurring "through the necessity to remain in control and to deny the presence of stress and ambiguity" (p. 49). This tension seems particularly significant when working with vulnerable populations. This caring has consequences for faculty, potentially linking to burnout (Teven, 2007).

Given the state of higher education, faculty must navigate the shifting identity demands of professoriate and new care labor demands, for which they may or may not be prepared or trained to perform. This piece seeks to provide a more concrete understanding of this new labor as well as how faculty discursively negotiate the move to adopt this labor. Utilizing a qualitative approach, this study explores 
the everyday experience of faculty working with emerging majority populations to develop a framework for understanding the identity negotiations experienced because of these significant changes to performance expectations and the adaptations they must make to fulfill these new roles.

\section{Methods}

\section{Participants}

A total of 19 faculty members participated from a regional, minority-majority Midwestern university south of a major metropolitan area before the first two authors were confident they had reached phenomenological saturation (VanManen, 1990). There were 13 females and six male participants. Not all participants indicated race/ethnicity, but of those that did, 11 indicated White/Caucasian, three Hispanic/Latinx, two Black/African American, and one Asian. A third $(n=6)$ of the respondents reported an income commensurate of lower-middle class. Roughly another third (8) reported being middle class and two reported a family income in the upper middle-class range. One individual did not report. All participants had terminal degrees; 16 participants had PhDs and 3 had MFAs. Professors were employed in various positions. The sample contained eight lecturers, six assistant professors, three associate professors, and two full professors. Professors also represented various disciplines: anthropology, biology, communication, English, fine arts, global studies, history, humanities, marketing, mathematics, psychology, and sociology. The participants' average number of years teaching college was 6 (range 1-23). Of the participants, 13 indicated they had some teacher training in their graduate programs.

\section{Procedures}

To provide a comprehensive view of the issues of identity negotiations, care labor, and teaching, researchers triangulated methods of data collection (Denzin, 1978; Patton, 1999). Focus group interviews often provide more detail regarding organizational relationships (McDonald \& Farrell, 2012). Individual interviews allow for more rich descriptions and add depth to perspectives (Carter et al., 2014). By triangulating the data and using various methods, this analysis provides an interpretation of emotional labor in academia.

An email was sent to faculty who taught in the general education curriculum as these faculty have more contact with emerging-majority students. Faculty were asked to volunteer for either a focus group lasting $1 \frac{1}{2}-2$ hours or an individual interview lasting approximately 1 hour (please contact authors for protocol). Focus group participants were incentivized by providing meals and snacks. Individual interviewees were given a small stipend. All participants were asked to complete demographic questionnaires and consent forms prior to interviews. Three focus groups consisted of a total of nine participants. The average interview length was 81 minutes. Ten individual interviews were completed. The average length was 56 minutes (range $=42-103$ minutes). Funding for the study was provided by an internal grant.

\section{Data Analysis}

Both during the transcription process and during the analysis, the first and second authors engaged in memoing (Glesne, 2006). Memoing allowed the authors to create notes about what appeared important or interesting. The researchers performed constant comparative method of data analysis on the 241 pages of transcripts (Glaser \& Strauss, 1967; A. Strauss \& Corbin, 1998). This allowed for data reduction into manageable fragments (A. L. Strauss, 1987). First, the researchers began by reading several interview 
transcripts and writing memos about possible thematic categories, utilizing in vivo coding (Saldana, 2013) when it seemed appropriate. An example of an in vivo code was a "check-in." The researchers made notes and comments to return to with the other researchers. Researchers were able to discuss possible categories, and potential differences in participants' descriptions. When more specific themes emerged, the authors began to re-code the original data with the newer, emerging themes. Themes were separated on Word documents and comparisons were continued in an iterative process until primary and secondary themes emerged. Additionally, after themes emerged, these themes were brought back to two of the participants to engage in member checking to strengthen the validation process. The two individuals selected for member checks were included as they provided diversity in gender, ethnicity, nationality, and divergence in academic ranks and thus offered maximum demographic variation to allow for the most diverse perspectives. Individuals were given a copy of the themes developed and asked for their feedback as suggested by Creswell (2007); participants who took part in the member check process agreed with the themes. Validation was also conducted through triangulation of data (Creswell, 2007), which involves the comparison of multiple forms of evidence from focus groups and individual interviews (Lindlof \& Taylor, 2002). Additionally, at the start of the study the first two authors held detailed discussions to both understand and limit the impact of researcher bias in the interview protocol and also coding, as the first author is a member of the community under investigation. Creswell (2007) argued that clarifying research "bias" is something that should be explicated at the start so that individuals understand the perspective of the researcher. Further, additional members of the university and other scholars were involved in the study as they offered the opportunity of peer review. Peer review or debriefing allowed us to add in the perspectives of individuals who both (1) Have firsthand experience with the phenomena under investigation and (2) Have experience in researching emotional labor (Creswell, 2007). Validation was also enhanced through the use of thick, rich descriptions in the results, which allows readers to evaluate the quality and transferability of the themes (Creswell, 2007).

\section{Results}

The purpose of this project was to examine the lived experiences of professors working in an institution serving emerging majority students. For this paper, we focus on the negotiation of the role of faculty members in and outside the classroom. Two major themes emerged-role strain and intrusive teaching as care labor.

\section{Role Strain}

Faculty role strain can be defined as the moments where individuals articulated struggle in their work responsibilities, often with competing demands for time and energy. Several tensions emerged between professors' idealized expectations and realistic workloads. Faculty explained their roles in and out of the classroom in interesting and sometimes shocking ways. Faculty articulated a need to set boundaries on their assignment of duties and also expressed a struggle to do so, particularly in regard to what they felt their roles should be in relation to students. Some participants articulated an obligation to care for and address the emotional, social, and physical well-being of the student as an implicit part of their assigned duties even when it presented personal costs.

"Not a counselor." Often individuals spoke about the limits of their roles. "Not a counselor" can be defined as incidences where faculty communicated a struggle with what they felt were activities outside of their professional expertise or their role as instructors. Christina explained, 
Like I've had students who want to come to talk to me about their problems and then they start talking about their marriage problems or something. I'm like, all right. So, I think that's part of the reason that I'm like, boundaries, boundaries, boundaries so um it's hard to find that balance of ... providing students with resources, but also being their professor.

Luciana expressed frustration that as a professor she was doing the work of counseling_ "both doing therapy at work and being a teacher and being an instructor and when I'm not really a licensed counselor, you know?" She asserted that this work contains elements of licensed therapy which exists outside her role. Overall, individuals were able to demarcate the work that shouldn't be included, yet they were performing regardless.

For some, the line of where the job of professor ends and where the duties of counselor begins are unclear. Role strain occurs in the moments in which professors were unsure as to where labor landedas their responsibility or as something beyond them. Meera explained,

I don't know what it is. What/where does it stop? . . . because it's never been discussed ... it's not something which is ... So, in terms of clear boundaries in the sense that as an instructor, as a teacher, sometimes you can define yourself as hey, my job is to ensure that people accomplish the learning objective outcomes of the course. Beyond that, everything else is outside my role. Because my role is that of an instructor ... When it comes to these personal cases though, it is not defining those learning outcomes. It goes outside those proscriptions.

For Meera, acting "outside of the proscriptions" was a necessity in order for some of her students to be a part of the learning environment. Emily's response conveyed an air of ambivalence to the effect this may have on her professional and emotional well-being when she said twice, "it's fine ... I'll deal with"; this betrays the emotional work associated with such a role strain of being a professor and resource-provider while also trying to engage in her own self-care.

"Moral Compunction." Some faculty situated the strain of expanded responsibilities within the context of the student experience. Thus, "moral compunction" was an argument about the moral imperative that someone somehow must find a way to be the support system these students need in the absence of students feeling empowered enough to seek out available services on their own, if the campus even had the necessary resources for students. This was also a reflection on the perception that the university appeared to be failing to provide student support needs to adequately address the exceptionality of the student experience. Carolyn commented,

Yeah. So I kind of go into sort of like the superhero mode. Like, wanting to solve their problems for them and make everything right. And that can be very frustrating because I don't think that's what I should do. I don't think that's what ... I don't think that's my role. That's just sort of my personality. Like with my kids, I don't want them to ever suffer anything. But they have to go through their own challenges to figure things out, so that they can become strong and capable adults. Right? So I kind of take that same, the way in which I want to protect my children. [Emphasis added]

Erin expressed a similar sense of duty to respond to the human conditions of her students. She stated, "I try to take solace in that I think that I'm doing the best that I can and that I do care. I'm trying to get 
help. I'm not turning a blind eye to these things, but I also have to remind myself I can't fix the world. They're coming out of situations where they've often been failed systemically."

Taken together the participants' discourse illustrates role strain as they navigate competing identity roles. For many, this was a struggle between defining the role of the immediate teacher and creating space for the larger "professor" role among predominately marginalized student populations. Faculty expressed the tensions between performances they saw as "counselor" roles, juxtaposed to the necessities of operating under an awareness of the systematic oppressions which have affected the student as a whole person-between what one ought to do in terms of a job description and what one might feel compelled to do as a human being responding to another human being.

\section{Intrusive Teaching}

In the previous theme, we saw the faculty give voice to a struggle in understanding new behavioral expectations, seen as the change in labor "requirements." These labor requirements are reinforced by current social norms in higher education to "serve students," which led some professors to take on a series of extraordinary behaviors which we termed intrusive teaching. Intrusive teaching can be defined as the ascribed supportive role that requires excessive commitment with individual students. Intrusive teaching is made up of demands on time, extensive student management, and long-term relationship maintenance.

Availability/Time. Faculty expressed a need to be available to their students at nearly every hour of the day and well outside the bounds of traditional office hours. Emily told the story of one student who was experiencing mental health issues for whom she attempted to provide extensive advice:

If I mentioned [to students], "Maybe you should think about seeing a counselor outside of here," the look on their face is like, "What?" and they have no idea how to even seek that [service] out. [My] students [were] texting me this morning, [and I said to one] "Why not look online to see if the counseling center deals with these issues?" But, she doesn't feel comfortable going there so she's got to go through and channel it through me. Which ... [is] fine. That's fine. I'll deal with it but I'm not experienced in that.

This professor, in her attempt to be available to her students, received texts at all hours from struggling students. Similarly, the need to be continuously available was echoed by Angela. She commented about a particular student, "He just needed a lot of reassurance and support, and I had to go over his grade with him over and over again like 'If this, then that, and if you make sure that you study, you should be fine." She explained how the student thanked her at the end of the semester and then continued, "I feel like getting that kind of positive feedback makes it worth it too because if I said that we probably exchanged 50 emails over two classes, I don't think that would be exaggerating. It might even be more. He was very needy." The exceptionality of the student experience appeared to provoke professors to go to great lengths to ensure student success outside of the normative role expectations of faculty. William echoed the time demands of being faculty-as-resource provider in the classroom spaces:

Here it's just not only different in degree, it's different in quantity ... so to be really doing the kind of interventions both outside the classroom and inside the classroom that I would like to be doing ... if there's a critical mass and just because of how some things work out and how the students themselves relate to each other when it's the whole class ... the amount of emotional 
labor that's required both of the students and of me and one-on-one and follow-up . . but fuck, that's tiring when you're doing it for a lot of students in one term.

As William stated, the sheer quantity of students in each class that need additional time and attention can add to an enormous amount of labor. At this teaching institution, faculty are often teaching three or more classes per semester. The percentage of students with exceptional circumstances can mean 75 to $80 \%$ of the class is dealing with at least one issue influencing academic performance. Attempting to assist in helping students manage issues left faculty feeling overwhelmed.

Check-ins. Faculty also articulated a series of ever-increasing "intervention" behaviors that they used to monitor the students. In the theme of check-in, faculty spoke of instances when they were concerned in which they would actively seek personal information from the student regarding their personal lives. Christina described her efforts to ensure that her students were succeeding by reaching out and heading off issues by investigating problems before they impeded completion of the course.

All I see are the symptoms of it, and it's hard to tell. Is this student missing class because they have another obligation, they've got a job and they're tired, they're struggling with transportation issues, they're having substance abuse problems? ... I don't know what the issue is, so all I can try to do is treat the symptom: "You're not showing to class, you need ... " I'll send them an email, "You've missed several classes, you're falling behind on assignments, we need to get a plan to get you caught back up." .. . Well, I think that part of the satisfaction of it is by heading off the issues beforehand that's a lot less traumatic when things really don't go right. If you think about it and you plan for it, fewer things go wrong so it's not as emotionally draining. It might be a little bit more work on your part to get things set up but the payoff is things run a little bit more smoothly.

Students suddenly disappearing from class appeared to raise a red flag for faculty and Meera compared her reaction to others. She stated,

But, yeah, there have been situations where stories have been . . . it's basically the way as an instructor and ... I find these issues is when they're not performing. That's a red signal! ... if somebody is not ... is lagging behind and not performing well, I will ask them what is going on. I'm not an instructor who will just, ... just ignore it, this is how we are. Because I want to know, and I tell them that if you are absent in class-and I put a lot of emphasis on this-if it's a lecture-based, campus-based class, you have to show up. ... And so, I do check on people, because I think you need to, because you don't know what is going on. It could be something worse.

In Meera's quotation, she speaks to how "we are," thus illustrating the normative behavior of checking in for this group of faculty. Faculty described these actions as being "proactive" about potential issues that may hinder the student performance in the course and, potentially, the overall well-being of the student. Guilia explained,

I think I tend to be more proactive about reaching out to students, particularly with the firstyear students. ... I tend to be much more proactive about contacting them if I haven't seen them in a while or, and using [student alert software] that flag it in the system. And then, I'll usually send the student an email directly because nobody likes getting an email from a 
system that's like, "You haven't been in class." And so, I'll send them something more like, "I'm concerned about you. How are you doing? Please check in with me.” And usually they'll reply.

This first level of intervention occurs when students are members of the instructor's course. Faculty appear to be monitoring student behaviors for signs of personal distress and reaching out to students to encourage them to share that distress so that issues with course completion can be addressed as quickly as possible.

Required Relationships. Faculty attempted to delineate labor they thought might cross a professional boundary with actions that represent a "human" response to the situation. Required relationships represented the interaction that faculty described when they were compelled to go beyond the typical instructor role and not only provide interpersonal support, but also extend their relationships beyond the semester. For many, like Meera, they listened: “They are anxious, looking for someone to listen to their story ... So I just listen as a friend, and then as an advisor . . . kind of a thing. Just so they can be successful in their class." Faculty like Meera argued that students just needed someone to listen, and then they could proceed with their work. Listening became an assumed part of duties. These same faculty felt that they did not cross the line into counseling work if they only listened. But, "listening as a friend, and then as an advisor" shows how the role of faculty is constraining when the boundaries between faculty and student are muddled out of human compassion and necessity of circumstances as faculty are increasingly compelled by administrators to "serve students" in ways that are beyond the expectations of faculty.

Further, faculty mentioned "tracking" students in subsequent semesters, even when those students have moved on and out of their classes. Mark described his experience with a student and discussed his plans for reaching out to the student. "The student moved into Section 8 housing this past semester. I haven't seen her yet on campus this semester so I'm going to email her over the spring break just to check in." Carolyn mirrored this need to continue to monitor the student's progress and her confusion over what she is legally allowed to discover:

When you see what happens... Sometimes I'll try to follow up on the student the following semester ... There's one kid from last semester, I haven't been able to find where he landed in the second writing class [or] if he managed to stay at the university. Then you get into FERPA stuff too, right? Can I go around and ask? I'd love to know how this kid's doing, what classes he's in, but I don't know that I can do that.

Although faculty expressed the need to address student emotional and mental well-being as it influences classroom performance, they also clearly struggle with a desire to remain informed and involved in the students' lives after official relationships have ended, contributing to the role strain of faculty.

Interventions. A final level of intervention occurred when faculty made decisions to advocate on behalf of the student or make decisions for the student outside of the role expectations of faculty. Interventions can be defined as times when faculty felt that they were compelled to act outside of their role as professors. Camila explains,

One student was struggling to finish a paper for my class and she wanted to come talk to me about it. ... But then, it became very clear that it wasn't just the paper itself, it wasn't like she didn't know ... she was a great writer. Right? She was just very, very overwhelmed with her 
own mental health and with her struggles. And so, she kind of broke down in my office. And it became clear she needed to go to counseling. I just walked her out to the [counseling center]. And she couldn't - when we got up into the counter, she couldn't even speak for herself ... So, because I intervened, she did start getting some counseling. She did start getting her medication, which her parents had been very opposed to. But she did that and was much ... I mean, that's the pressure on that issue of much healthier, happier the next semester.

In Camila's explanation, taking action was necessary at a particular moment, even though it is outside of the responsibilities of higher education faculty to do so. Similarly, other faculty commented about the need to intervene in the student decision-making process. Emily commented, "And then I'm like, 'It took me this much time to convince them to even go down [to the Counseling and Wellness Center] with me.' It was me holding their hand and dragging them kicking and screaming a little bit." For these faculty members, interventions were necessary for the well-being of the student. Throughout the interviews, faculty spoke of the need for constant check-ins with current students, beyond the boundaries of the normal office hour interactions. They also spoke about establishing relationships that were almost required of them so students could be successful. Finally, they also felt the expectation to intervene in students' lives outside the classroom, all of which helped establish the expectation of intrusive teaching.

\section{Discussion}

Faculty expressed a series of care labor demands whereby they became responsible for the student as a whole person, not simply as a student with whom which they had a contractual obligation to provide a grade for the semester. The degree of student issues that hindered classroom performance and the severity of these issues influenced increasing involvement into students' lives. Faculty articulated a new modus operandi-intrusive teaching-where the emotional and social aspects of students' lives were equally relevant, discoverable, and managed as was student mastery of content. Based on these expectations of intrusive teaching, we also saw the faculty coming to terms with these identity conflicts in their discussions of role stain.

The care labor being defined here under the term intrusive teaching was not readily accepted by faculty with some pushback to these perceived responsibilities framed under the context of "serving students." Faculty often initially rejected (even when later adopting) what they perceived to be ascribed duties belonging to other professional identities when they discussed "not being a counselor" and not being a "social worker," jobs which would presumably require an individual to become intimately involved in the social, emotional, and environmental issues influencing psychosocial well-being. Still others appeared to struggle with what was being required of them under the "serving students" norm set by the institution, as well as with what was possible in terms of their expertise and ability and with the impacts on their classroom spaces, scholarship expectations, and personal time. These framings speak back to earlier work by Anderson et al. (2019) in their framing of role overload. Rather than talking back to these added demands, some faculty justified their care labor in terms of their personal moral philosophies. These constructions of moral imperatives tie back to career trajectories that build narratives of calling (Hagmaier \& Abele, 2012). Perceiving the students to be without support and facing difficult obstacles, faculty suggested it was a just and moral human response to take on care labor. In this framing, the faculty enact identities that center on the devoted professor role. Future research in instructional communication should explore the consequences for faculty who embrace narratives of calling with other outcomes like job satisfaction and retention. 
This continued commitment to the role of teacher requires faculty hold the role of teacher as more salient in their identity hierarchy than other roles associated with their jobs, such as that of the researcher (Hogg et al., 1995), or possibly debate the identity salience of worker versus romantic partner, parent, and so forth. On one hand, faculty appear to understand that the tasks they set before themselves cannot possibly be accomplished with $100 \%$ success. Yet, they also appear compelled to add these extra duties and responsibilities. Faculty, for fear of losing first-year students in vast numbers and desiring to be omnipresent for students, enact behaviors that allow them to continue to profess an enlightenment ideal of education. The normative value that every student should get a college education and everyone should have an equal opportunity might mean that universities are creating directives to enroll and retain students who do not have the emotional or mental capacity to be successful at that particular moment. Rather than resist, faculty live up to these new role expectations and take on the additional care labor of providing support they are ill-equipped to provide. Future research should explore how role salience for faculty teaching at these types of institutions influences management of role conflict with other aspects of their lives such as partner or parent.

While student affairs and administrative offices typically create the programs and services for students (Kerby, 2015), it is the faculty who are tasked with the uncompensated physical and emotional labors associated with the changing role sets for faculty (Anderson et al., 2019; Lawless \& Chen, 2019; Stern \& Denker, 2020). This role strain can come at a considerable emotional and professional cost to the faculty, but a cost some faculty feel morally compelled to pay in order to successfully serve students.

These new care labor demands resulted in a set of behaviors termed intrusive teaching, which were teaching behaviors seen as essential for students to function within the classroom space and proceed with their education. This reframing posits the student-faculty relationship into long-term relationships as required for more students instead of the historical mentoring models (Waldeck et al., 1997). It results in changes to both the nature and volume of faculty labor. Moreover, as Hogg and Terry (2000) argued that uncertainty leads to more social identity processing, we can imagine that more faculty will continue to experience the tensions of role strain as they negotiate the uncertainty that is higher education in this moment and continue to hear calls to be the stopgap for recruitment and retention issues on campus. Instructional communication scholars should continue to attend to identity issues in faculty as we move forward in this cultural moment and try to adjust for the upcoming changes.

This manuscript gives voice to the role strain of the faculty participants in this study when teaching emerging-majority student populations, but is not making any value-judgments on the current ethos of public universities as places where faculty "serve students." It is not for us to say whether this is what faculty should or should not be doing with regard to professor-student relationships or for the enrollment and retention needs of public universities. It is, however, critically important to understand that the experiences of these professors will cease to be extraordinary and will become much more common in the future (Merisotis \& McCarthy, 2005). Preparing future faculty and our current colleagues for these changes will be essential. Despite a necessity to substantiate that this additional labor has the intended consequence of increased retention (Tinto, 2006), there is an emerging body of literature regarding the unintended effects (King \& Wheeler, 2019). In this we echo the calls of other instructional communication scholars arguing for more instructional training (e.g., Anderson et al., 2019; Lawless \& Chen, 2019). These calls need to be shared with administrators so that they can best support the front lines of retention care labor. In addition, we agree that the value of this labor in professional evaluation must be demonstrated if faculty choose or are "encouraged" to participate in the labor. The psychosocial 
messages caring laborers receive from their work groups could be a key way in which they make sense of their emotional labor. Work groups satisfy psychological needs for individuals, such as belonging, feeling distinct, exerting control, as well as serve as sources of support, encouragement, and advice (Moreland et al., 2001). Faculty support groups for institutions facing these challenges could potentially provide emotional outlets for faculty and opportunities for sense-making as individuals struggle with identity and boundary management and care labor demands.

\section{Conclusion}

An altered identity of the faculty role within the professoriate appears to have translated into a series of extraordinary behaviors. In this new campus culture, faculty are expected to serve and retain students through actively being a part of student lives, while simultaneously maintaining professional boundaries and authoritative control of classroom spaces. Researchers should explore what characteristics make faculty more likely to engage in this care labor of intrusive teaching and how this might influence emotional and mental well-being. As student populations across the globe continue to transform and retention becomes a concern for us all, so too will the need to change the performance of the professoriate, and the experiences these faculty face today will soon become the norm. This study examines a rich area of inquiry, especially relevant for administrators and policymakers when developing best practices for teaching, learning, retention, and persistence in higher education.

\section{References}

Anderson, E. L. (2003). Changing U.S. demographics and new directions in higher education. New Directions for Higher Education, 121, 3-12. https://doi.org/10.1002/he.97

Anderson, L. B., Ruiz-Mesa, K., Jones-Bodie, A., Waldbuesser, C., Hall, J., Broeckelman-Post, M. A., \& Hosek, A. M. (2019). I second that emotion: A collaborative examination of emotions felt in course administration work. Journal of Contemporary Ethnography, 49(2), 201-228. https://doi. org/10.1177\%2F0891241619873130

Araújo, N., Carlin, D., Clarke, B., Morieson, L., Lukas, K., \& Wilson, R. (2014). Belonging in the first year: A creative discipline cohort case study. The International Journal of the First Year in Higher Education, 5(2), 21-31. https://doi.org/10.5204/intjfyhe.v5i2.240

Athens, W. (2018). Perceptions of the persistent: Engagement and learning community in underrepresented populations. Online Learning, 22(2), 27-58. https://files.eric.ed.gov/fulltext/EJ1181406.pdf

Bean, J. P., \& Metzner, B. S. (1985). A conceptual model of nontraditional undergraduate student attrition. Review of Educational Research, 55(4), 485-540. http://rer.sagepub.com/content/55/4/485.short

Betances, S. (2004). How to become an outstanding educator of Hispanic and African American first-generation college students. In F. W. Hale Jr. (Ed.), What makes racial diversity work in higher education (pp. 44-59). Stylus.

Bourdieu, P. (1986). The forms of capital. In J. G. Richardson (Ed.), Handbook of theory and research for the sociology of education (pp. 241-258). Greenwood Press.

Burke, P. J. (1980). The self: Measurement requirements from an interactionist perspective. Social Psychology Quarterly, 43, 18-29. https://www.jstor.org/stable/3033745

Cabrera, A. F., Nora, A., \& Castaneda, M. B. (1993). College persistence: Structural equations modeling test of an integrated model of student retention. Journal of Higher Education, 64(2), 123-139. https:// doi.org/10.1080/00221546.1993.11778419 
Carlson, S. (2019, November 9). Why being a provost is one of the toughest jobs at vulnerable colleges. The Chronicle of Higher Education. https://www.chronicle.com/article/Why-Being-a-Provost-IsOne-of/247514

Carter, N., Bryant-Lukosius, D., DiCenso, A., Blythe, J., \& Neville, A. J. (2014). The use of triangulation in qualitative research. Oncology Nursing Forum, 41, 545-547. http://doi.org/10.1188/14.ONF.545-547

Chronicle of Higher Education. (2019). The Looming Enrollment Crisis. Report.

Creswell, J. W. (2007). Qualitative inquiry and research design: Choosing among five traditions (2nd ed.). Sage.

Crissman Ishler, J. L. (2005). Today’s first-year students. In M. L. Upcraft, J. N. Garner, \& B. O. Barefoot (Eds.), Challenging and supporting the first year student (pp. 15-26). Jossey-Bass, Wiley.

Denzin, N. K. (1978). Sociological methods: A sourcebook. McGraw-Hill.

Dougherty, D. S., \& Drumheller, K. (2006). Sensemaking and emotions in organizations: Accounting for emotions in a rational(ized) context. Communication Studies, 57(2), 215-238. https://doi. org/10.1080/10510970600667030

Erickson, R., \& Ritter, C. (2001). Emotional labor, burnout, and inauthenticity: Does gender matter? Social Psychology Quarterly, 64(2), 146-143. https://www.jstor.org/stable/3090130

Erickson, R. J., \& Stacey, C. L. (2013). Attending to mind and body: Engaging the complexity of emotion practice among caring professionals. In A. A. Grandey \& J. Diefendorff (Eds.), Emotional labor in the 21st century: Diverse perspectives on the psychology of emotion regulation at work (pp. 175-196). Routledge Academic.

Fineman, S. (1993). Emotion in organizations. Sage.

Glaser, B. G., \& Strauss, A. L. (1967). The discovery of grounded theory: Strategies for qualitative research. Aldine Publishing Company.

Glesne, C. (2006). Becoming qualitative researchers: An introduction (3rd ed.). Pearson.

Hagmaier, T., \& Abele, A. E. (2012). The multidimensionality of calling: Conceptualization, measurement and a bicultural perspective. Journal of Vocational Behavior, 81, 39-51. https://doi.org/10.1016/j. jvb.2012.04.001

Hochschild, A. R. (1983). The managed heart: Commercialization of human feeling. University of California.

Hogg, M. A., \& Terry, D. I. (2000). Social identity and self-categorization processes in organizational contexts. Academy of Management Review, 25(1), 121-140. https://doi.org/10.5465/amr.2000.2791606

Hogg, M. A., Terry, D. J., \& White, K. M. (1995). A tale of two theories: A critical comparison of identity theory with social identity theory. Social Psychology Quarterly, 58, 255-269. http://doi. org/10.2307/2787127

Horn Jr., R. A. (2003). Developing a critical awareness of the hidden curriculum through media literacy. Clearing House, 76(6), 298-300. https://doi.org/10.1080/00098650309602024

Hosek, A. M. (2015). The intergroup perspective in the classroom: An examination of group-based categorization and relational outcomes between students and teachers. Communication Research Reports, 32(2), 185-190. https://doi.org/10.1080/08824096.2015.1016146

Hosek, A. M., \& Soliz, J. (2016) Expanding the landscape of diversity in instructional communication research through the intergroup perspective. Communication Education, 65(2), 223-226. https://doi. org/10.1080/03634523.2015.1098714

Hrabowski, F. (2005). Fostering first-year success of underrepresented minorities. In M. L. Upcraft, J. N. Gardner, \& B. O. Barefoot (Eds.) Supporting first-year students: A handbook. (pp. 125-140). Jossey-Bass. 
Kelderman, E. (2019, May 20). Enrollment shortfalls spread to more colleges. The Chronicle of Higher Education. https://www.chronicle.com/article/Enrollment-Shortfalls-Spread/246341

Kerby, M. B. (2015). Toward a new predictive model of student retention in higher education: An application of classical sociological theory. Journal of College Student Retention: Research, Theory \& Practice, 17(2), 138-161. http://doi.org/10.1177/1521025115578229

Kimbark, K., Peters, M. L., \& Richardson, T. (2017). Effectiveness of the student success course on persistence, retention, academic achievement, and student engagement. Community College Journal of Research and Practice, 41(2), 124-138. http://doi.org/10.1080/10668926.2016.1166352

King, M. E., \& Wheeler, A. (2019). Reducing secondary trauma and compassion fatigue in the dark side of interpersonal communication classrooms. Journal of Communication Pedagogy, 2, 90-95. https:// doi.org/10.31446/JCP.2019.17

Laden, B. V. (2004). Serving new majority students. New Directions for Community Colleges, 127, 5-19. http://doi.org/10.1002/cc.160

Lawless, B. (2018). Documenting a labor of love: Emotional labor as academic labor. Review of Communication, 18(2), 85-97. https://doi.org/10.1080/15358593.2018.1438644

Lawless, B., \& Chen, Y. W. (2019). "You have to cry before you teach this class": Emotion with work and resistance in teaching intercultural communication. Journal of Communication Pedagogy, 2, 63-75. https://doi.org/10.31446/JCP.2019.14

Lindlof, T. R., \& Taylor, B. C. (2002). Qualitative communication research methods (2nd ed.). Sage.

Lohfink, M., \& Paulsen, H. (2005). Comparing the determinants of persistence for first-generation and continuing-generation students. Journal of College Student Development, 46, 409-428. http://doi. org/10.1353/csd.2005.0040

Longwell-Grice, R. (2003). Get a job: Working class students discuss the purpose of college. The College Student Affairs Journal, 22(2), 40-53.

Mastracci, S. H., Guy, M. E., \& Newman, M. A. (2012). Emotional labor and crisis response: Working on the razor's edge. M. E. Sharpe.

McDonald, D., \& Farrell, T. (2012). Out of the mouths of babes: Early college high school students' transformational learning experiences. Journal of Advanced Academics, 23(3), 217-248. https://doi. org/10.1177\%2F1932202X12451440

Mead, G. H. (1934). Mind, self, and society. University of Chicago Press.

Merisotis, J. P., \& McCarthy, K. (2005). Retention and student success at minority-serving institutions. New Directions For Institutional Research, 125, 45-58. http://doi.org/10.1002/ir.138

Mitchell, M., Leachman, M., Masterson, K., \& Waxman, S. (2018, October 4). Unkept promises: State cuts to higher education threaten equity and access. Center on Budget and Policy Priorities. https://www. cbpp.org/research/state-budget-and-tax/unkept-promises-state-cuts-to-higher-education-threatenaccess-and

Moreland, R. L., Levine, J. M., \& McMinn, J. G. (2001). Self-categorization and work-group socialization. In M. A. Hogg \& D. J. Terry (Eds.), Social identity processes in organizational contexts (pp. 87-100). Taylor and Francis.

NSC Research Center. (2019, September 26). Tracking Transfer. https://nscresearchcenter.org/signature report13/

O'Keeffe, P. (2013). A sense of belonging: Improving student retention. College Student Journal, 47(4), 605-613.

Patton, M. Q. (1999). Enhancing the quality and credibility of qualitative analysis. Health Sciences Research, 34, 1189-1208. https://www.ncbi.nlm.nih.gov/pmc/articles/PMC1089059/ 
Pearson, J. C., Child, J. T., DeGreeff, B. L., Semlak, J. L, \& Burnett, A. (2011). The influence of biological sex, self-esteem, and communication apprehension on unwillingness to communicate. Atlantic Journal of Communication, 19(4), 216-227. https://doi.org/10.1080/15456870.2011.584509

Putnam, L. L., \& Mumby, D. K. (1993). Organizations, emotion, and the myth of rationality. In S. Fineman (Ed.), Emotion in Organizations (pp. 36-57). Sage.

Saldana, J. (2013). The coding manual for qualitative researchers (2nd ed.). Sage.

Sass, J. S. (2000). Emotional labor as cultural performance: The communication of caregiving in a nonprofit nursing home. Western Journal of Communication, 64(3), 330-358. https://doi. org/10.1080/10570310009374679

Smith, B. (2013). Mentoring at-risk students through the hidden curriculum of higher education. Roman \& Littlefield.

Soria, K. K., \& Stebleton, M. J. (2012). First-generation students' academic engagement and retention. Teaching in Higher Education, 17(6), 673-685. https://doi.org/10.1080/13562517.2012.666735

Stern, D. M., \& Denker, K. J. (2020). Privileged vulnerability: Embodied pedagogy as critical rhetorical praxis. International Journal of Communication, 14, 799-812. https://ijoc.org/index.php/ijoc/article/ view/8483

Strauss, A., \& Corbin, J. (1998). Basic of qualitative research: Techniques and procedures for developing grounded theory (2nd ed.). Sage.

Strauss, A. L. (1987). Qualitative analysis for social scientists. Cambridge University.

Stryker, S. (1968). Identity salience and role performance: The importance of symbolic interaction theory for family research. Journal of Marriage and the Family, 30(4), 558-564. https://www.jstor.org/ stable/349494

Teven, J. (2007). Teacher temperament: Correlates with teacher caring, burnout, and organizational outcomes. Communication Education, 56(3), 382-400. https://doi.org/10.1080/03634520701361912

Tinto, V. (1987, Fall). The principles of effective retention [Paper presentation]. Maryland College Personnel Association, Largo, MD, United States.

Tinto, V. (2006). Research and practice of student retention: What next? Journal of College Student Retention, 8(1), 1-19. https://doi.org/10.2190\%2F4YNU-4TMB-22DJ-AN4W

VanManen, M. (1990). Researching lived experience: Human science for an action sensitive pedagogy. State University of New York Press.

Waldeck, J. H., Orrego, V. O., Plax, T. G., \& Kearney, P. (1997). Graduate student/faculty mentoring relationships: Who gets mentored, how it happens, and to what end. Communication Quarterly, 45(3), 93-109. https://doi.org/10.1080/01463379709370054

Whitford, E. (2019, August 7). A new dropout risk: Students responsible for aging or sick relatives. The Chronicle of Higher Education. https://www.chronicle.com/article/A-New-Dropout-Risk-Students/ 246898 